\title{
EDUCAÇÃO ESPECIAL NA PERSPECTIVA INCLUSIVA NO ENSINO SUPERIOR: ESTUDO SOBRE EDUCANDOS COM DEFICIÊNCIA
}

\author{
Dorcely Isabel Bellanda Garcia ${ }^{1}$ \\ Maria Luiza da Luz Munhoz ${ }^{2}$
}

GARCIA, D. I. B.; MUNHOZ, M. L. da L. Educação especial na perspectiva inclusiva no ensino superior: estudo sobre educandos com deficiência. EDUCERE - Revista da Educação, Umuarama, v. 20, n. 1, p. 187-209, jan./jun. 2020.

RESUMO: O objetivo deste artigo é discutir acerca da inclusão de alunos com deficiência no ensino superior; mais especificamente na Universidade Estadual do Paraná (Unespar), campus de Paranavaí, no Curso de Pedagogia. Este estudo de cunho qualitativo e quantitativo foi motivado por estes questionamentos: existem alunos em situação de inclusão no curso de Pedagogia? Quais são as condições para o acesso, a inclusão e a permanência dos educandos durante a graduação? Quais são as condições de acessibilidade arquitetônica e pedagógica?. Para respondê-los, foram realizadas pesquisas bibliográficas e de campo. Em relação aos resultados, os dados demonstram que há dois alunos em situação de inclusão no curso de Pedagogia. Além disso, foi possível constatar que, apesar do avanço na legislação referente às políticas públicas da Educação Especial na Perspectiva Inclusiva, em termos de efetivação, as dificuldades são imensas. Quem frequenta o curso aponta que entre as maiores dificuldades estão a ausência de acessibilidade arquitetônica e pedagógica, a falta de recursos financeiros, físicos e humanos para assegurar a aprendizagem dos alunos com deficiência. Conclui-se que, apesar de inúmeros encaminhamentos legais acerca da educação inclusiva, são grandes os complicadores para o acesso, a permanência e a conclusão do curso de graduação.

DOI: 10.25110/educere.v20i1.2020.7475

${ }^{1}$ Doutora em Educação e Graduada em Psicologia/UEM. Coordenadora do Núcleo de Educação Especial Inclusiva/NESPI. Líder do Grupo de Pesquisa GEPEEIN/Pesquisadora da UNESPAR/ Campus Paranavaí. Docente do Curso de Pedagogia e do Mestrado em Educação Inclusiva PROFEI. E-mail: dorcelygarcia@hotmail.com

${ }^{2}$ Acadêmica do curso de Pedagogia. Bolsa PIBIC/UNESPAR/ Campus Paranavaí (Atualmente graduada em Pedagogia). E-mail: marialuiza_munhoz@hotmail.com 
$\mathrm{Na}$ instituição pesquisa, por exemplo, a efetivação dos direitos humanos de estudantes com deficiência ainda não se concretiza plenamente, embora existam ações em prol da inclusão.

PALAVRAS-CHAVE: Educação Inclusiva; Ensino superior; Curso de Pedagogia.

\section{SPECIAL EDUCATION OF DISABLED STUDENTS IN THE INCLUSIVE PERSPECTIVE ON HIGHER EDUCATION}

ABSTRACT: The purpose of this article is to discuss the inclusion of disabled students in higher education, specifically in the State University of Paraná (Unespar), Paranavaí campus, at the Pedagogy Course. This qualitative and quantitative study was motivated by the following questions: are there students in an inclusive situation in the Pedagogy Course? What are the conditions for the access, inclusion, and permanence of these students during the undergraduate course? What are the architectural and pedagogical accessibility conditions? To answer them, a literature review and a field research were made. Regarding the results, the data shows that there are two students in an inclusive situation in the Pedagogy Course. Additionally, it was possible to verify that, despite the progress made by the legislation regarding Public Policies for Special Education in the Inclusive Perspective, there are huge difficulties in terms of application. Those who attend the course point out that amongst the greatest difficulties there is the lack of architectural and pedagogical accessibility as well as the lack of financial, physical, and human resources to ensure the learning of disabled students. It can be concluded that, despite numerous legal texts on inclusive education, there are great complications for the access, permanence, and completion of graduation courses. In the researched institution, for example, the effectiveness of the human rights of students with disabilities is not yet complete even though actions have been taken for inclusion.

KEYWORDS: Inclusive Education; Higher Education; Pedagogy Course. 


\section{EDUCACIÓN ESPECIAL CON PERSPECTIVA INCLUSIVA EN LA ENSEÑANZA SUPERIOR: ESTUDIO SOBRE EDUCANDOS CON DEFICIENCIA}

RESUMEN: El objetivo de este artículo es discutir acerca de la inclusión de estudiantes con deficiencia en la enseñanza superior; mas específicamente en la Universidade Estadual do Paraná(Unespar), campus de Paranavaí, en el Curso de Pedagogía. Este estudio de alcance cualitativo y cuantitativo fue motivado por los siguientes cuestionamientos: ¿Existen estudiantes en situación de inclusión en el curso de Pedagogía? ¿Cuáles son las condiciones para el acceso, la inclusión y la permanencia de los educandos durante la graduación? ¿Cuáles son las condiciones de accesibilidad arquitectónica y pedagógica? Para contestarlos, se realizaron estudios bibliográficas y de campo. En relación a los resultados, los datos demuestran que hay dos estudiantes en situación de inclusión en el curso de Pedagogía. Además de eso, ha sido posible constatar que, a pesar del avance en la legislación referente a las políticas públicas de la Educación Especial en la Perspectiva Inclusiva, en términos de efectividad, las dificultades son inmensas. Quien frecuenta el curso señala que entre las mayores dificultades están la falta de accesibilidad arquitectónica y pedagógica, la falta de recursos financieros, físicos y humanos para asegurar el aprendizaje de los estudiantes con deficiencia. Se concluye que, a pesar de innúmeras remisiones legales acerca de la educación inclusiva, son grandes los factores que complican el acceso, la permanencia y la conclusión del curso de graduación. En la institución investigada, por ejemplo, la efectividad de los derechos humanos de estudiantes con deficiencia aún no se concretiza plenamente, aunque existan acciones en pro de la inclusión.

PALABRAS CLAVES: Educación Inclusiva; Enseñanza Superior; Curso de Pedagogia.

\section{INTRODUÇÃO}

O intuito deste estudo é verificar como ocorre a inclusão e a permanência de alunos com deficiência no ensino superior, no Curso de Pedagogia da Universidade Estadual do Paraná (Unespar), Campus de Paranavaí. 
Trata-se de uma pesquisa de caráter quantitativo e qualitativo, realizada por meio de levantamento bibliográfico, de leituras de artigos científicos, de análise de documentos legais sobre as Políticas Públicas da Educação Especial na Perspectiva da Educação Inclusiva (PNEEPEIN). Foi realizada, também, pesquisa de campo, por meio de coleta de dados, sobre o número de alunos em situação de inclusão no curso já citado. A coleta foi realizada no banco de dados do Núcleo de Educação Especial Inclusiva (NESPI) desta universidade, o qual foi criado e regularizado pela Resolução 007/2016 - Memorando n. ${ }^{\circ}$ 35/2016 COU/Unespar/Pró-reitoria de ensino e graduação. Vale destacar também a Portaria n. ${ }^{\circ} 716 / 2016$, que criou o Centro de Educação em Direitos Humanos da Unespar (CEDH) e os seus respectivos núcleos, dentre eles o NESPI. A coleta foi autorizada pela coordenadora do Nespi, nomeada por meio da Resolução N. ${ }^{\circ}$ 007/2016 - COU/Unespar, de 06 de Setembro de 2016 e renomeada em 2018 pela Portaria No 009/2018 - DG.

Referente à metodologia utilizada neste artigo, primeiramente, a pesquisa centrou-se sobre a PNEEPEEIN, com ênfase no ensino superior. Na sequência, foi realizada a coleta de dados no banco de dados do NESPI sobre o número de educandos com deficiência, bem como relatos desses alunos e da coordenadora do Curso de Pedagogia acerca das condições de acesso e de permanência durante a graduação. Para finalizar, realizaram-se o tratamento analítico dos dados da pesquisa e a sistematização dos resultados.

\section{POLÍTICA PÚBLICAS INCLUSIVAS}

É importante marcar, conceitualmente, que deficiência é aqui definida como qualquer perda ou anormalidade da estrutura, seja ela psicológica, fisiológica ou anatômica. De acordo com a Organização Mundial da Saúde (OMS) de acordo com dados de 2011, “[...] um bilhão de pessoas vivem com alguma deficiência - isso significa uma em cada sete pessoas no mundo". Desta maneira, como qualquer outra pessoa, indivíduos com deficiência possuem inúmeros direitos, dentre eles a educação de qualidade em todos os níveis de ensino (UNESCO, 2011).

O número de alunos com deficiência e aqueles considerados pú- 
blico alvo ${ }^{1}$ da educação especial na rede regular de ensino, em particular, nas universidades, aumentou de forma acelerada nos últimos anos. Segundo o censo realizado pelo Instituto Nacional de Estudos e Pesquisas Educacionais (INEP) no ano de 2013 "Os censos da Educação Superior registram que, entre 2003 e 2012, o número de estudantes passou de 5.078 para 27.143 estudantes, representando um crescimento de 534\%".

A Lei de Diretrizes e Bases da Educação de 2013 (LDB) assegura ao educando o acesso, a inclusão e a permanência no ensino superior e a qualidade em todos os níveis de ensino. Segundo os artigos 58 e 59 da LBD, n. ${ }^{\circ}$ 12.796/2013, a Educação Inclusiva é compreendida como uma categoria da educação escolar, em particular, na rede de ensino regular, que garante aos educandos com deficiência, por meio das políticas públicas inclusivas, acesso a professores capacitados para a inserção dos estudantes em salas de aula comuns ou, em alguns casos, a inclusão deles em instituições especializadas, além de métodos e de técnicas pedagógicas para atender as suas dificuldades.

A PNEEPEIN consiste, dentre outros encaminhamentos, no Atendimento Educacional Especializado (AEE) por meio de um trabalho pedagógico em escolas e/ou em universidades, ou seja, em todos os níveis de ensino, para estudantes que possuem deficiência. $\mathrm{O}$ intuito é elevar o andamento do processo de ensino e de aprendizagem a estes educandos. $\mathrm{O}$ Estado tem o compromisso e o dever de promover ao cidadão acesso à educação de qualidade, assim como elucida o artigo $2 .^{\circ}$ da Lei Federal n. ${ }^{\circ}$ 7.853, de outubro de 1989:

Art. $2^{\circ}$ Ao Poder Público e seus órgãos cabe assegurar às pessoas portadoras de deficiência o pleno exercício de seus direitos básicos, inclusive dos direitos à educação, à saúde, ao trabalho, ao lazer, à previdência social, ao amparo à infância e à maternidade, e de outros que, decorrentes da Constituição e das leis, propiciem seu bem-estar pessoal, social e econômico. Na área da educação: a) a inclusão, no sistema educacional, da Educação Especial como modalidade educativa que abranja a educação pre-

\footnotetext{
${ }^{1}$ Alunos que possuem deficiência física, intelectual e/ou sensorial, transtornos globais do desenvolvimento (autismo, síndrome do espectro do autismo e psicose infantil) e altas habilidades/superdotação.
} 
coce, a pré-escolar, as de $1^{\circ}$ e $2^{\circ}$ graus, a supletiva, a habilitação e reabilitação profissionais, com currículos, etapas e exigências de diplomação própria; b) a inserção, no referido sistema educacional, das escolas especiais, privadas e públicas; c) a oferta, obrigatória e gratuita, da Educação Especial em estabelecimento público de ensino; d) o oferecimento obrigatório de programas de Educação Especial a nível pré-escolar, em unidades hospitalares e congêneres nas quais estejam internados, por prazo igual ou superior a 1 (um) ano, educandos portadores de deficiência; e) o acesso de alunos portadores de deficiência aos benefícios conferidos aos demais educandos, inclusive material escolar, merenda escolar e bolsas de estudo f) a matrícula compulsória em cursos regulares de estabelecimentos públicos e particulares de pessoas portadoras de deficiência capazes de se integrarem no sistema regular de ensino [...] (BRASIL, 1989, p. 1).

Há, todavia, falta de documentos, de estudos científicos, de relatos, de artigos e de reflexões sobre como ocorre a inclusão de alunos com deficiência nas Instituições de Ensino Superior (IES), evidenciando a dificuldade na elaboração de políticas públicas que garantem ao estudante o acesso e a permanência nesta modalidade de ensino. Uma das consequências da ausência desses estudos mais aprofundados sobre a temática é a dificuldade na formação e no aperfeiçoamento de conhecimentos de professores para que atuem com esses educandos. Sobre tal questão, Santos (2002) discorre que:

Os estudos de Mattei e Haiduke (2010), Menezes (2010), Pereira (2008), Oliveira (2011) e Silva e Frota (2011) alertam para a necessidade de aprofundamento de pesquisas acerca das Políticas de Inclusão para o Ensino Superior, um campo que ainda se considera 'minado' por apresentar interpretações e traduções dessas políticas de forma específica e em alguns pontos divergentes (SANTOS, 2002, p. 2). 
A primeira manifestação de documentos legais sobre a Educação Especial na Perspectiva Inclusiva nas IES foi o Aviso Curricular n. . 277, de 8 de maio de 1996 do Ministério da Educação (MEC), o qual apresenta vários modos de acesso e de permanência no ensino superior para pessoas com deficiência; eles englobam tanto o edital, os critérios de avaliação e os recursos na prova de vestibular quanto a acessibilidade arquitetônica e os métodos pedagógicos, podendo, portanto, alcançar níveis cada vez mais elevados no processo educacional.

A Educação Especial na Perspectiva da Educação Inclusiva possui uma defasagem de informações acerca das IES, dificultando a elaboração de políticas públicas que garantam ao estudante o acesso e a permanência em uma determinada graduação. Outro fator relevante são as estruturas físicas que dificultam o acesso do aluno com deficiência nas universidades. Para Mantoan (2006), a redução de indivíduos com Necessidades Educacionais Especiais (NEE) nas IES é resultado das discriminações sofridas pelas pessoas com deficiência ao longo da história da humanidade.

A falta de profissionais qualificados no ensino superior para lidarem com alunos com deficiência é um dos fatores que preocupam os estudiosos da Educação Especial na perspectiva inclusiva, uma vez que esse profissional mediará o conteúdo para o aluno.

No ano de 2002, as Diretrizes Curriculares Nacionais para a Formação de Professores da Educação Básica [...] destacam que as instituições de ensino superior devem prever, em sua organização curricular, formação docente voltada para a atenção à diversidade e que contemple conhecimentos sobre as especificidades dos alunos com necessidades educacionais especiais no mesmo ano, reconhece a Língua Brasileira de Sinais - LIBRAS [...] como meio legal de comunicação e expressão, determinando que sejam garantidas formas institucionalizadas de apoiar seu uso e difusão, bem como a inclusão da disciplina de LIBRAS no currículo nos cursos de formação de professores e de fonoaudiologia (SANTOS, 2002, p. 15). 
Nesse contexto, é possível verificar que a qualidade de ensino do aluno com deficiência não está apenas voltada às questões de acessibilidade arquitetônica ou de adaptação curricular, mas também, em primeiro lugar, a professores e a profissionais aptos para lidarem com a inclusão, de modo a proporcionarem ao estudante a mediação pedagógica do conteúdo a fim de possibilitar a assimilação dos conteúdos trabalhados durante a aula.

Referente ao Estado do Paraná, há documentos específicos sobre os encaminhamentos da Educação Especial no Estado. Um exemplo é a Deliberação n. ${ }^{\circ}$ 02/2016, de 15 de setembro de 2016, que prevê aos educandos com deficiência o AEE em qualquer nível de ensino, etapa ou modalidade, sendo ele complementar ou suplementar como parte do processo educacional. O AEE, segundo o documento, deverá garantir o aprendizado do estudante ao longo de sua vida, já que ele passará por todos os níveis da educação básica e do ensino superior, assim, poderá desenvolver as suas potencialidades e habilidades (PARANÁ, 2016). Com esse documento, o Paraná é o único estado que oferece AEE em Sala de Recursos Multifuncionais (SRM) para os educandos com transtornos funcionais específicos.

Ainda no Paraná, existe a Instrução n. ${ }^{\circ}$ 09/2018-SUED/SEED, a qual discorre e prevê os critérios de atendimentos em SRM e quais as deficiências abrangidas por ela ${ }^{2}$. A instrução também relata qual é o tipo de avaliação necessária para a inserção desses educados nas SRM. Além disso, o documento traz como deve ser a organização do atendimento perante cada deficiência, enfatizando a sistematização dos elementos que constituem as SRM (PARANÁ, 2018).

Até aqui, foram apresentados os encaminhamentos das políticas públicas que garantem ao educando com deficiência o acesso e a permanência na rede regular de ensino, assegurando o AEE em SRM. Foi constatado, por meio de leituras bibliográficas, como ocorre a inclusão desses educandos no contexto escolar, bem como a ausência de profissionais capacitados para lidarem com tal situação na escola. Dessa maneira, na próxima seção, discute-se a inclusão de estudantes com deficiência no

\footnotetext{
${ }^{2}$ As Salas de Recursos Multifuncionais (SRM), no Estado do Paraná, abrangem a deficiência intelectual, a deficiência física neuromotora, os transtornos globais do desenvolvimento, as altas habilidades e a superdotação e os transtornos funcionais específicos, como dislexia, disortografia, disgrafia, discalculia e Transtorno do Déficit de Atenção com Hiperatividade (TDAH) (PARANÁ, 2018).
} 
ensino superior, dando início às discussões sobre a inclusão na IES.

\section{EDUCAÇÃO ESPECIAL NO ENSINO SUPERIOR}

A PNEEPEIN define a inclusão como a inserção de alunos com deficiência na rede regular, em todos os níveis de ensino, para que consigam aprender com seus pares, sem sofrer qualquer tipo de discriminação. Desse modo, há leis que garantem e asseguram a execução desse direito, como a meta 4 do Plano Nacional de Educação de 2014 (PNE).

De acordo com a meta 4 do PNE (2014), alunos de 4 a 17 anos que apresentam deficiência física, Transtornos Globais do Desenvolvimento (TGD), Altas habilidades ou Superdotação (AH/SD) possuem acesso ao AEE e direito ao sistema educacional inclusivo, além do ingresso às SRM na rede regular de ensino. O objetivo da lei é garantir ao educando a inserção em salas de aula comuns e professores com formação específica, uma vez que eles são os responsáveis pela medição de conhecimentos científicos no contexto escolar.

Uma das primeiras manifestações de leis que asseguram o direito de permanência nas IES foi a Lei Federal n. ${ }^{\circ}$ 10.436, aprovada em abril de 2002 que regulamenta a difusão da Língua Brasileira de Sinais (LIBRAS) e da Língua Portuguesa para o acesso dos surdos à educação. Conforme o seu Art. 3. ${ }^{\circ}$, a LIBRAS deve ser inserido, de forma obrigatória, no currículo dos cursos de formação de professores; o objetivo é fornecer condições aos futuros docentes para que possam lidar com alunos surdos com o auxílio de uma intérprete.

No ano de 1998, em Paris, ocorreu a Conferência Mundial sobre a Educação Superior. Nessa situação, foram discutidos os seguintes aspectos: no que consiste a educação no ensino superior ${ }^{3}$ e quais são os seus princípios. Dessa forma, algumas missões e funções do ensino superior foram desenvolvidas, como a igualdade de acesso, a qual permite que todos os indivíduos possam ingressar no ensino superior, mesmo que contenham algum tipo de deficiência. De acordo com a Declaração Universal de Direitos Humanos:

Educação superior não deve ser baseada no mérito,

\footnotetext{
${ }^{3}$ De acordo com a Conferência Mundial sobre a Educação Superior (1998), em instituições como universidades e/ou estabelecimentos aprovados pelas autoridades do Estado e que fornecem estudo ou formação em níveis pós-secundário para a pesquisa.
} 
capacidade, esforços, perseverança e determinação mostradas por aqueles que buscam o acesso à educação, e pode ser desenvolvida na perspectiva de uma educação continuada no decorrer da vida, em qualquer idade, considerando devidamente as competências adquiridas anteriormente. Como consequência, para o acesso à educação superior não será possível admitir qualquer discriminação com base em raça, sexo, idioma, religião ou em considerações econômicas, culturais e sociais, e tampouco em incapacidades físicas (UNESCO, 1998, p. 7).

A partir dessa Conferência, o ingresso de pessoas com deficiência nas universidades deve proporcionar uma nova visão em relação ao termo 'inclusão', a qual é colocada em prática por meio de currículos, de metodologias, de avaliações e de preparo do corpo docente para lidar com tal situação. Já na elaboração do currículo, a instituição deve levar em consideração a identidade de cada aluno para que assegure, de forma concreta, a aprendizagem. Sobre a educação inclusiva, Glat e Pletsch falam que:

A Educação Inclusiva é aquela responsável em proporcionar ao aluno com necessidades educativas especiais a participação em todas as atividades propostas e que ocorrem em sala de aula, de forma que todos estejam engajados e aprendendo os mesmos conteúdos, com ou sem a utilização de metodologias diferenciadas (GLAT; PLETSCH, 2004, p. 213).

Dessa forma, a educação especial na perspectiva inclusiva consiste em disponibilizar ao educando não apenas o acesso à universidade, mas sim condições de permanência no ensino de qualidade, proporcionando todos os seus direitos, conforme o Art. 59 da LDB de 1996:

Os sistemas de ensino assegurarão aos educandos com necessidades especiais: I - currículos, métodos, técnicas, recursos educativos e organização específicos, para atender às suas necessidades; II - terminalidade específica para aqueles que não puderem atingir o nível exigido para a conclusão do ensino 
fundamental, em virtude de suas deficiências, e aceleração para concluir em menor tempo o programa escolar para os superdotados; III - professores com especialização adequada em nível médio ou superior, para atendimento especializado, bem como professores do ensino regular capacitados para a integração desses educandos nas classes comuns; IV - educação especial para o trabalho, visando a sua efetiva integração na vida em sociedade, inclusive condições adequadas para os que não revelarem capacidade de inserção no trabalho competitivo, mediante articulação com os órgãos oficiais afins, bem como para aqueles que apresentam uma habilidade superior nas áreas artística, intelectual ou psicomotora; V - acesso igualitário aos benefícios dos programas sociais suplementares disponíveis para o respectivo nível do ensino regular (BRASIL, 1996, p. 19).

O MEC publicou por meio da Portaria Normativa ME n. ${ }^{\circ} 14$, de 24 de abril de 2007, a regulamentação do processo de acessibilidade para a educação no ensino superior. Segundo o Art. $1 .^{\circ}$ desse documento, o Programa Incluir é criado com o intuito de implantar e de consolidar núcleos de acessibilidade para promover ações e garantir o acesso pleno das pessoas com deficiência, ou seja, possibilitar condições de permanência para esses estudantes.

A inclusão no ensino superior deve proporcionar ao estudante todo conhecimento necessário para a sua formação, havendo a criação de metodologias, de adaptações e de técnicas, conforme a sua necessidade. Nesse sentindo, a próxima seção retrata, a partir da análise de dados coletados pelas autoras no Nespi da instituição em 2017, como ocorre a inclusão no Curso de Pedagogia ofertado no campus de Paranavaí da Unespar.

\section{EDUCAÇÃO INCLUSIVA NA UNESPAR, CAMPUS DE PARA- NAVAÍ}

Na Unespar, campus de Paranavaí há o Centro de Educação em Direitos Humanos (CEDH) que é composto por três núcleos: o Núcleo 
de Educação Especial e Inclusão (NESPI), o Núcleo de Educação para Relações Étnico-Raciais (NERA) e o Núcleo de Educação para Relações de Gênero (NERG), cujo objetivo é orientar e organizar ações de apoio a necessidades de grupos vulneráveis para o seu acesso, a sua inclusão e a sua permanência no ensino superior. Além disso, tais núcleos têm o objetivo de promover o desenvolvimento de perspectivas educacionais e sociais inclusivas e uma cultura de valorização à diversidade e de defesa dos direitos humanos na Unespar. O CEDH, a partir de 2016, foi estruturado e formalizado em todos os campi da instituição (CEDH/UNESPAR, 2016), seguindo a Resolução n. ${ }^{\circ}$ 007/2016 - COU-UNESPAR e a Portaria n. ${ }^{\circ} 013 / 2016$ - DG.

Dentre os núcleos citados, escolheu-se discorrer acerca do Nespi, uma vez que ele retrata a Educação Especial na perspectiva inclusiva na instituição, que também é o tema deste artigo:

O intuito primordial do NESPI é executar ações de acesso, inclusão e permanência de indivíduos com deficiência (física neuromotora, intelectual, sensorial), transtornos globais do desenvolvimento, altas habilidades/superdotação e acometimentos físicos ou psicológicos permanentes ou transitórios que dificultem seu desenvolvimento acadêmico em iguais condições com os demais alunos (CEDH/NESPI, 2016, p. 1).

Uma das funções do NESPI é manter atualizado o banco de dados sobre educandos com deficiência na instituição, para que sejam acompanhados e que sejam oferecidas as acessibilidades pedagógica e arquitetônica a eles, bem como para que outras ações e outros encaminhamentos necessários que fazem parte das funções desse núcleo sejam tomados.

No ano de 2017, para atualizar o banco de dados, os membros do NESPI, com a sua coordenadora criaram um Cadastro de Acessibilidade cujo objetivo era buscar informações sobre o número de alunos com deficiência, bem como a visão desses estudantes acerca das acessibilidades arquitetônica e pedagógica na Unespar, campus de Paranavaí. Os acadêmicos dos 11 cursos de graduação, ofertados em diferentes períodos, responderam ao cadastro que continha questões específicas, objetivas e 
subjetivas sobre possíveis deficiências dos discentes; algumas delas foram especificadas no cadastro, como deficiência auditiva, surdez, baixa visão, cegueira, deficiência física neuromotora, deficiência intelectual, altas habilidades/superdotação, transtornos globais do desenvolvimento, transtornos funcionais específicos, transtornos psíquicos e tratamento de saúde.

Foi encaminhado, também, a todos os coordenadores dos colegiados um cadastro contendo questões abertas sobre o seu olhar em relação às condições de entrada e de permanência dos acadêmicos com deficiência na instituição. Como tais informações eram recentes e foram coletadas em todos os cursos da instituição, as pesquisadoras buscaram, neste setor, os dados necessários para o estudo. O resultado - disponibilizado pela coordenadora do NESPI - encontra-se a seguir.

Gráfico 1: Cadastro dos discentes público alvo da Educação Especial na Unespar, campus de Paranavaí, em 2017

\section{DADOS SOBRE O CADASTRO DOS DISCENTES PÚBLICO ALVO DA EDUCAÇÃO ESPECIAL}
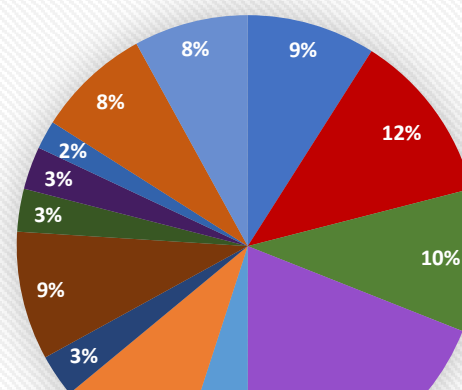

$9 \%$

$19 \%$

$5 \%$

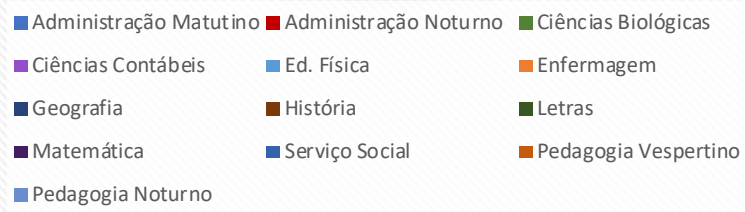

Fonte: Nespi/Unespar/campus de Paranavaí (2017). 
No Gráfico 1, está especificado o percentual de alunos com deficiência e demais transtornos por curso; no entanto, esses dados computaram também os alunos que não têm laudo médico, uma vez que a maioria não o possui. $\mathrm{O}$ número de alunos que relata possuir deficiência ou transtornos são os seguintes: Administração (matutino) - 19 alunos; Administração (noturno) - 25 alunos; Ciências Biológicas - 20 alunos; Ciências Contábeis A - 39 alunos; Ciências Contábeis B - 19 alunos; Educação Física - 10 alunos; Enfermagem - 19 alunos; Geografia - 7 alunos; História - 18 alunos; Letras -6 alunos; Matemática -6 alunos; Serviço Social - 5 alunos; Pedagogia (vespertino) - 16 alunos; Pedagogia (noturno) - 16 alunos. No total, 1062 alunos da Unespar responderam ao Cadastro, enquanto 649 deixaram de respondê-lo.

Gráfico 2: Educandos com laudo médico referente à sua deficiência.

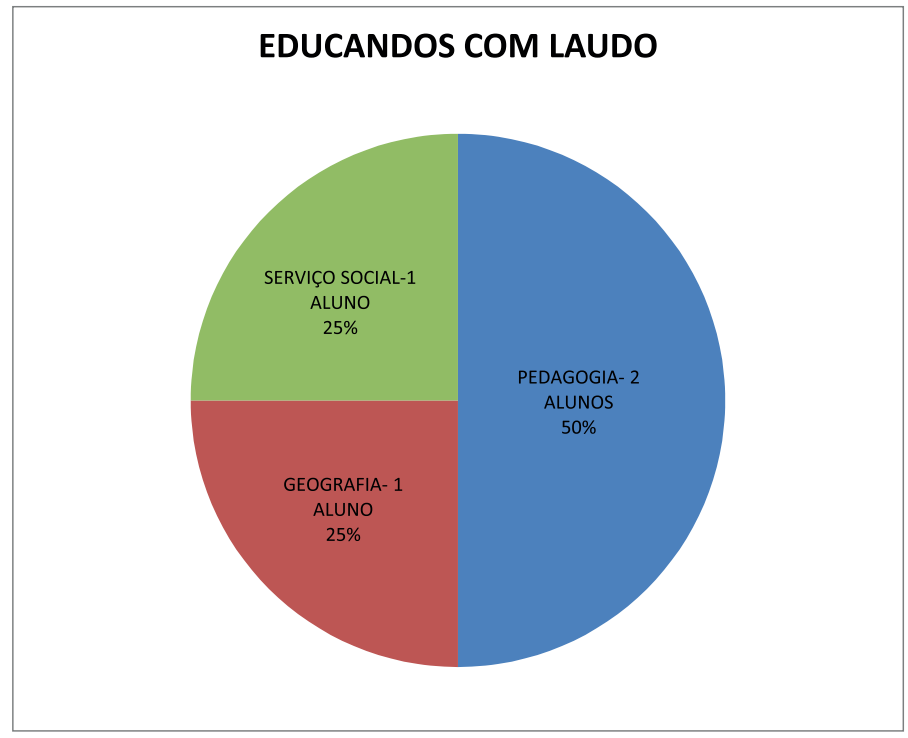

Fonte: Nespi/Unespar/campus de Paranavaí (2017).

No Gráfico 2, foram considerados somente o número de educandos que apresentaram laudo médico e o respectivo percentual corresponde considerando educandos com deficiência na instituição. A partir desse levantamento, encontraram-se os dados sobre os educandos em situação 
de inclusão no curso de Licenciatura em Pedagogia da Unespar, campus de Paranavaí, períodos vespertino e noturno. Foi constatado que, no Curso de Pedagogia vespertino, há dois alunos com deficiência com laudos comprobatórios de suas respectivas deficiências, sendo um aluno surdo e uma aluna com deficiência física neuromotora.

Gráfico 3: Dados sobre o cadastro de discentes do Curso de Pedagogia na Unespar, campus de Paranavaí

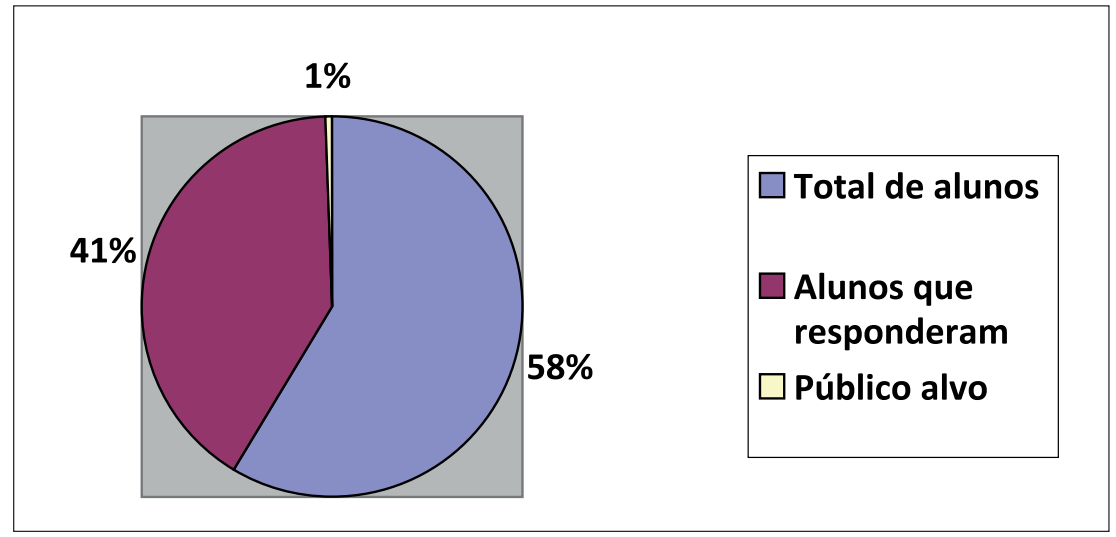

Fonte: Nespi/Unespar/campus de Paranavaí (2017).

Do total de alunos que frequenta o curso de Pedagogia, como especificado no Gráfico 3, 58\% não responderam ao cadastro, dos $41 \%$ que responderam ao cadastro não apresentaram laudo médico sobre alguma deficiência; apenas $1 \%$ apresentou laudos, os quais estão arquivados no Nespi, para comprovar a sua deficiência.

Para verificar sobre o acesso, a inclusão e a permanência de alunos com deficiência no ensino superior, no Curso de Pedagogia, após identificar quem são os alunos com deficiência que apresentam laudo, foi realizada a coleta de dados do Cadastro de Acessibilidade o qual continha questões abertas, as quais foram respondidas pelos acadêmicos e pelos coordenadores dos 11 cursos da instituição. Para ilustração, algumas questões foram estas: quais são as condições de acessibilidade que permitem a entrada destes estudantes neste nível de ensino e as condições de permanência no contexto inclusivo? Qual é o olhar dos acadêmicos 
e da coordenação sobre os alunos com deficiência e em situação de inclusão na IES? Referente à acessibilidade arquitetônica e pedagógica da instituição, o que tem a dizer?

Por meio da coleta de dados existentes no banco de dados do Nespi, nos Cadastros de Acessibilidade dos alunos e da coordenadora do Curso de Pedagogia, alguns pontos foram destacados, como a falta de professores capacitados para lidarem com os alunos em situação de inclusão, a demora e, principalmente, a dificuldade para contratação de professor intérprete.

De acordo com Santos (2015), a inclusão está primeiramente ligada a professores aptos para lidarem com alunos com deficiência com o objetivo de assegurar, da melhor forma, que ele internalize os conteúdos científicos transmitidos em sala de aula. A seguir, é apresentado um registro de um dos alunos do Curso de Pedagogia que possui deficiência:

[...] Uma das minhas maiores dificuldades encontradas aqui na universidade é a falta de professores que saibam lidar com a minha deficiência no contexto inclusivo. Possuem muita dificuldade em encontrar ou criar uma metodologia que atenda minhas necessidades em sala de aula, pois eles não têm o conhecimento especifico sobre como trabalhar com os discentes em situação de inclusão (Educando com deficiência/banco de dados NESPI, 2017).

Além da falta de professores aptos, alguns outros levantamentos destacam-se no cadastro respondido pela coordenadora do Curso, assim como evidencia o registro a seguir:

[...] Para atender um aluno com deficiência auditiva era necessário a contratação de um professor intérprete, porém tivemos várias dificuldades. Primeiramente, na região onde se encontra a universidade, é dificil ter esse profissional. Quando o profissional foi contratado, houve morosidade referente ao seu pagamento por parte do estado o que dificultou sua permanência como intérprete a este educando. Provocou a troca de muitos intérpretes, seja pela fal- 
ta deste profissional na região, seja pelo atraso do pagamento de seu salário. Após terem conseguido este profissional para permanecer 20 horas como intérprete e regulamentarem a forma de pagamento, ainda eram necessários aumentar a carga horária de 20 horas para 40 horas semanais. No curso de Pedagogia tem regência (estágio nas escolas), o aluno precisava de acompanhamento nos estágios obrigatórios do curso. Até conseguir ampliar a carga horária foi um grande desafio. O aluno ficou um período grande sem intérprete no horário que fazia sua regência (Educando com deficiência/banco de dados NESPI, 2017).

No registro do aluno com deficiência auditiva, a demora na contratação do profissional intérprete atrapalhou na internalização de determinados conteúdos; consequentemente, houve uma grande defasagem na obtenção de conhecimentos científicos durante a sua formação. $\mathrm{Na}$ sequência, o olhar e as experiências do estudante na posição de acadêmico:

[...] Quando iniciei o curso ainda não tinha intérprete à minha disposição, demorou alguns meses para que fosse contratado, e quando finalmente isso aconteceu houve o problema no pagamento de salário, o intérprete ficou três meses sem receber e então ele decidiu sair. Um tempo depois, foi chamado um novo intérprete, porém aconteceu a mesma coisa. Algum periodo depois, teve uma nova intérprete que está até hoje, após muito sacrifício para a realização de um processo seletivo. Toda essa transição ocasionou na dificuldade de aprender alguns conteúdos, que hoje faz falta para compreender outros (Educando com deficiência/banco de dados NESPI, 2017).

Outro aspecto relatado pelos estudantes é o sentimento de "exclusão em um contexto inclusivo", ocasionado, frequentemente, pelos colegas de sala de aula, que, na maioria das vezes, recusam-se a realizar 
trabalhos, tarefas e avaliações com eles pelo fato de, possivelmente, desconfiarem da capacidade cognitiva desses alunos. Um dos discentes relata que

[...] Durante esses três anos que estou aqui na universidade vários alunos se recusaram a fazer trabalhos comigo, mesmo sabendo da minha deficiência auditiva. Além dos trabalhos, quando faço algumas perguntas em sala de aula para os professores, tem alunas que riem da minha pergunta, e isto me faz mal e achar que as minhas dúvidas não são importantes. [...] Desde que entrei na universidade sofro esse tipo de preconceito, poucas pessoas querem fazer alguma atividade comigo, na verdade isso vem desde quando eu estava no ensino médio. Já deixei de fazer trabalhos quando estava em uma equipe e me senti excluído (Educando com deficiência/banco de dados NESPI, 2017).

Uma das questões abertas a ser respondida no cadastro abordava a forma pela qual eles tiveram acesso ao ensino superior. Um aluno relatou que entrou na universidade por meio do Sistema de Seleção Unificada (Sisu), que consiste na utilização da nota do Exame Nacional do Ensino Médio (Enem) para preencher vagas destinadas a esse programa. O outro estudante disse que o acesso à universidade foi pelo vestibular tradicional. A seguir, os depoimentos de ambos os alunos:

[...] Eu entrei na faculdade por meio do SISU, uma amiga que me falou sobre esse programa do governo e começamos a estudar para o ENEM, encontrei bastante dificuldade para estudar, porém enfrentei a minha dificuldade e fui fazer a prova e obtive a nota de 427,0. A qual foi suficiente para conseguir uma vaga pelo SISU e já estou no terceiro ano de Pedagogia (Educando com deficiência/banco de dados NESPI, 2017).

[...] Entrei na universidade pelo vestibular comum, na realidade participei do PROVAR [Processo Seletivo de Vagas Remanescentes] onde fui classificada de acordo com a minha nota da redação e fui con- 
vocada na segunda chamada (Educando com deficiência/banco de dados NESPI, 2017).

Dessa maneira, é possível constatar que a Unespar oferece meios de acesso além do vestibular tradicional (como o Sisu e o Provar) para os indivíduos que possuem deficiência e querem ingressar na universidade.

No cadastro da Coordenadora, por meio de questões abertas, ela deixou registrado que, nos últimos cinco anos, a universidade ainda não oferece e não possui recursos humanos, pedagógicos e financeiros para um ambiente inclusivo em relação às acessibilidades arquitetônica e pedagógica.

Quando houve obrigatoriedade, foram construídas rampas, banheiros adaptados, bem como houve a modificação do Projeto Político Pedagógico do curso. As condições objetivas, porém, ainda caminham na contramão de uma proposta inclusiva.

\section{CONCLUSÃO}

O objetivo deste artigo foi compreender e analisar as políticas públicas na perspectiva inclusiva no ensino superior e de que forma elas se concretizam na prática pedagógica, retratando a experiência da Unespar, campus de Paranavaí, com ênfase no curso de Licenciatura em Pedagogia. Dessa maneira, foi possível observar que, nos últimos anos, houve um aumento na discussão sobre a Educação Especial Inclusiva e que foram procurados caminhos para melhorar a qualidade da educação do público alvo nessa modalidade de ensino. Na instituição pesquisada, também foram observadas ações nesse sentido, tal como a criação do CEDH\NESPI em 2016.

Como consequência, foram elaboradas leis que preveem a educação inclusiva em todos os níveis de ensino. No entanto, a partir da análise dessas leis, bem como dos dados coletados no banco de dados do Nespi, foi possível perceber que, mesmo com a mudança significativa no modo de compreender os alunos com deficiência, ainda estão presentes atitudes, comportamentos, falta de estrutura física, acessibilidades arquitetônica e pedagógica que acabam dificultando a inclusão dos estudantes com deficiência, o seu acesso e a sua permanência. Quando esses alunos permanecem, trata-se de uma inclusão às avessas. 
Baseando-se nos fatos constatados, apesar de ainda haver muitos entraves que culminam em uma escola excludente, nota-se que há avanços em relação ao contexto escolar inclusivo na instituição. Por meio de verdadeiras políticas públicas inclusivas, os alunos com deficiência, que, historicamente, viveram à margem da sociedade, podem desenvolver as suas potencialidades juntamente com seus pares no âmbito educacional. A Unespar, embora em passos lentos ainda, por meio do CEDH/NESPI, está caminhando em direção a ações que priorizam os direitos humanos e as políticas de inclusão de seus educandos.

\section{REFERÊNCIAS}

BRASIL. Ministério da Educação. Aviso Curricular n. ${ }^{0}$ 277, de 8 de maio de 1996. Disponível em: portal.mec.gov.br/arquivos/pdf/ avisocircular277.pdf. Acesso em: 9 abr. 2019.

BRASIL. Ministério da Educação. Lei 7.853 de 24 de outubro de 1989. Dispõe sobre o apoio às pessoas portadoras de deficiência, sua integração social, sobre a Coordenadoria Nacional para Integração da Pessoa Portadora de Deficiência (CORDE), institui a tutela jurisdicional de interesses coletivos ou difusos dessas pessoas, disciplina a atuação do Ministério Público, define crimes e dá outras providências. Disponível em: http://www.planalto.gov.br/ccivil_03/leis/17853.htm. Acesso em: 16 abr. 2019.

BRASIL. Ministério da Educação. Lei no 9.394, de 20 de dezembro de 1996: Estabelece as diretrizes e bases da educação nacional. Diário Oficial [da] República Federativa do Brasil. Brasília, 23 dez. 1996. Disponível em: http://www.planalto.gov.br/ccivil_03/LEIS/L9394.htm. Acesso em: 9 abr. 2019.

BRASIL. Ministério da Educação. Lei 10.436, de 24 de abril de 2002. Dispõe sobre a Língua Brasileira de Sinais- Libras e dá outras providências. Brasília: MEC, 2002.

BRASIL. Ministério da Educação. Lei no 12.796, de 4 de abril de 2013. Altera a Lei $\mathrm{n}^{\circ}$ 9.394, de 20 de dezembro de 1996, que estabelece as 
diretrizes e bases da educação nacional, para dispor sobre a formação dos profissionais da educação e dar outras providências. Diário Oficial [da] República Federativa do Brasil. Brasília, 5 abr. 2013. Disponível em: http://www.planalto.gov.br/ccivil_03/_Ato2011-2014/2013/Lei/ L12796.htm. Acesso em: 30 ago. 2018.

BRASIL. Ministério da Educação. Lei no 13.005 , de 25 de junho de 2014. Aprova o Plano Nacional de Educação - PNE e dá outras providências. Diário Oficial [da] República Federativa do Brasil, Brasília, 25 jun. 2014. Disponível em: Portal Câmara dos Deputados. Acesso em: 15 nov. 2018.

BRASIL. Ministério da Educação. Marcos políticos-legais da educação especial na perspectiva inclusiva. Brasília, 2010.

BRASIL. Ministério da Educação. Portaria normativa no 14 , de 24 de abril de 2007. Dispõe sobre a criação do "Programa Incluir: Acessibilidade na Educação Superior”. Disponível em: portal.mec.gov. brlarquivos $\backslash$. Acesso em: 15 abr. 2019.

BRASIL. Ministério da Educação. Secretaria de Educação Especial. Política Nacional de Educação Especial na Perspectiva da Educação Inclusiva. Brasília: MEC/SEESP, 2008.

DECLARAÇÃO UNIVERSAL DOS DIRETOS HUMAMOS. Assembleia Geral das Nações Unidas em Paris. 10 dez.1948. Disponível em: www.ohchr.org \EN\UDHR \DOCUMENTOS. Acesso em: 14 abr. 2019.

GLAT, Rosana; PLETSCH, Marcia. Inclusão escolar de alunos com necessidades educacionais especiais. Rio de Janeiro: Wak, 2004.

INEP. Instituto Nacional de Estudos e Pesquisas Educacionais Anísio Teixeira. Diretoria de Avaliação da Educação Superior. Referenciais de acessibilidade na educação superior. São Paulo, 2013. Disponível em: www.inep.gov.br. Acesso em: 22 abr. 2018.

MANTOAN, Maria Tereza. Inclusão escolar: o que é? por quê? como 
fazer? 2. ed. São Paulo: Moderna, 2006.

NESPI. Núcleo de educação especial e inclusão. Universidade Estadual do Paraná. UNESPAR. Paranavaí, 2017.

PARANÁ. Deliberação n. ${ }^{0}$ 02/2016. Dispõe sobre as Normas para a Modalidade Educação Especial no Sistema Estadual de Ensino do Paraná. Curitiba: CEE, 2016. Disponível em: http://www.cee.pr.gov.br/ arquivos/File/pdf/Deliberacoes/2016/Del_02_16.pdf. Acesso em: 7 abr. 2019.

PARANÁ. Instrução n. ${ }^{0}$ 09/2018-SUED/SEED: Estabelece critérios para Atendimento Educaional Especializado por meio da Sala de Recursos Multifuncionais, nas áreas da deficiência intelectual, deficiência física neuromotora, transtornos globais do desenvolvimento e para estudantes com transtornos funcionais específicos nas instituições de ensino do Sistema Estadual de Ensino. Curitiba: 2018. Disponível em: http://www.educacao.pr.gov.br/arquivos/File/instrucoes/2018/ instrucao_092018.pdf. Acesso em: 9 abr. 2019.

SANTOS, Monica Pereira. Educação inclusiva: redefinindo a educação especial. Florianópolis, 2002.

UNESCO. Conferência mundial sobre a educação superior. Paris, 1998.

UNESCO. Pessoas com deficiência no Brasil. Brasil, 2011.

\section{UNIVERSIDADE ESTADUAL DO PARANÁ. PORTARIA N. ${ }^{\circ}$}

009/2018. Designa Coordenadora e vice do Centro de Acesso, Inclusão e Permanência da Diversidade Humana no Ensino Superior - CEDH. UNESPAR, 2018. Disponível em: http:/www.unespar.edu.br/a_reitoria/ atos-oficiais/reitoria/portarias/2018/portaria-n-o-009-2018-reitoriaunespar.pdf. Acesso em: 16 abr. 2019.

\section{UNIVERSIDADE ESTADUAL DO PARANÁ. PORTARIA N. ${ }^{\circ}$}

716/2016. Designa Coordenadora e vice do Centro de Acesso, Inclusão

e Permanência da Diversidade Humana no Ensino Superior - CEDH. 
UNESPAR, 2016. Disponível em: http://www.unespar.edu.br/a_reitoria/ atos-oficiais/reitoria/portarias/2016/portaria-n-o-716-2016-reitoriaunespar.pdf. Acesso em: 16 abr. 2019.

UNIVERSIDADE ESTADUAL DO PARANÁ. Projeto para a Criação do Centro de Acesso, Inclusão e Permanência da Diversidade Humana no Ensino Superior - CEDH. UNESPAR, 2016. Disponível em: http://www.unespar.edu.br/projetos/cedh. Acesso em: 9 abr. 2019.

\section{UNIVERSIDADE ESTADUAL DO PARANÁ. RESOLUÇÃO No}

007/2016. Dispõe sobre a criação do Centro de Acesso, Inclusão e Permanência da Diversidade Humana no Ensino Superior (CEDH) da Universidade Estadual do Paraná - UNESPAR e aprovação do seu Regimento Interno. UNESPAR, 2016. Disponível em: http:// www.unespar.edu.br/...reitoria/.../cou.../resolucao-007-2016-cou.../ Resolução\%20007_2. Acesso em: 16 abr. 2019.

Recebido em: 14/04/19 Aprovado em: 23/03/20 